\title{
Jerónimo Grimaldi, enviado extraordinario de la república de Génova en Madrid
}

\author{
PaUlino Rivero \\ UNED \\ Jerónimo Grimaldi, envoy extraordinary of the Republic \\ of Genoa to Madrid
}

\begin{abstract}
RESUMEN
Jerónimo Grimaldi y Pallavicini, embajador de España durante los reinados de Felipe V, Fernando VI y Carlos III y responsable de la primera secretaria de Estado y de Despacho entre 1763 y 1776, es una figura relativamente ausente de la investigación histórica. Este olvido es particularmente acusado en el caso de su actividad diplomática, que desempeñó durante más de tres décadas y que comenzó con su designación como enviado extraordinario de la república de Génova en Madrid.
\end{abstract}

PALABRAS CLAVE

Jerónimo Grimaldi / siglo XVIII / embajadores / secretarios de Estado /

Génova

\section{ABSTRACT}

Jerónimo Grimaldi y Pallavicini, ambassador in the service of Philip V, Ferdinand VI and Charles III, served as Spanish Chief Minister between 1763 and 1776. Grimaldi has been relatively forgotten by the Spanish historians. This fact is particularly remarkable if we take into account his extensive career as diplomat -more than thirty years-, whose first step was his appointment as envoy extraordinary of the Genoa republic to Madrid.

\section{KEY WORDS}

Jerónimo Grimaldi / 18th century / ambassadors / Chief Ministers / Genoa 
Pablo Jerónimo de Grimaldi y Pallavicini nació en la ciudad de Génova probablemente en el mes de julio de $1710^{1}$. Algunas fuentes hacen referencia al año 1709 y en otras, que descartaremos a este respecto por falta de consistencia con el resto de su biografía, se mencionan 1706, 1712 e incluso 1720². Bautizado como Girolamo Grimaldi en memoria de su tío paterno, el cardenal del mismo nombre, vino al mundo en el seno de la familia patricia genovesa formada por Francesco María di Raniero di Tomasso Grimaldi y por Giovanna di Giovanfrancisco Pallavicini y Spinola. La pareja se había desposado el 14 de febrero de 1700 y al nacer Girolamo ya tenía un hijo de cinco años, Raniero, siendo ambos los únicos frutos del matrimonio. El padre, Francesco María Grimaldi, era uno de los cuatro hijos de Raniero Grimaldi y de la española Jerónima Cuniquez. Gran propietario inmobiliario, comerciante emprendedor y marcadamente interesado en política, Francesco María Grimaldi había desempeñado en varias ocasiones funciones diplomáticas al servicio de Génova, primero en Francia, después en España como enviado extraordinario entre enero de 1713 y diciembre de 1715 y finalmente en Austria entre 1726 y $1727^{3}$.

El joven Girolamo, a quien nos referiremos en lo sucesivo por su nombre español, Jerónimo, pertenecía por línea paterna a la rama genovesa de la Casa de Grimaldi ${ }^{4}$. Los Grimaldi, con los Doria, Fieschi y Spinola constituían el núcleo principal de la aristocracia tradicional de la república, los «vecchi» o antiguos, así denominados en contraposición a los «nuovi», entre los que destacaban los Balbi, Moneglia, Saluzzo y Durazzo 5 . Tanto «vecchi» como «nuovi» quedaron agrupados en un «colegio» nobiliario único, los «alberghi», a partir de la reforma impuesta por Andrea Doria en 1528, que supuso la ruptura de la república con Francia y el comienzo de

1 En relación con la «sequía» historiográfica sobre Jerónimo Grimaldi, la única publicación especíifica a la que se ha tenido acceso, dedicada además a su etapa en la secretaría de Estado, es el artículo de JURETSCHKE, $\mathrm{H}$.: «El marqués de Grimaldi visto por los representantes diplomáticos de Viena acreditados en la Corte de Carlos III», en Cuadernos de la Escuela Diplomática, num. 3, (1989), pp. 65-83.

2 En la necrológica publicada con ocasión del fallecimiento de Jerónimo Grimaldi en la Gaceta de Madrid (23 de diciembre de 1789) se indica que tenía 83 años, lo que supone que habría nacido en 1706. D. OZANAM menciona 1709 como el año de su nacimiento (Les Diplomates Espagnols du XVIII Siecle, Madrid, 1998, p. 287). G. BENZONI, en su entrada correspondiente a Girolamo Grimaldi del Dizionario Biográfico degli Italiani, vol. 59, Roma, 2003, indica que fue bautizado el 6 de julio de 1710.

${ }^{3}$ En relación con el destino en España de Francesco María Grimaldi de nuevo se aprecian discrepancias. El conde de FERNAN NUÑEZ lo sitúa en 1712 en su Vida de Carlos III, Madrid, 1898, tomo II, nota a la p. 8, mientras que D. OZANAM (Les Diplomates..., p. 287), hace referencia a 1715. Puede encontrarse una referencia a su figura en CONSTANTINI, C. y BULFERETTI, L.: Industria e comercio en Liguria, Milán, 1966.

${ }^{4}$ De las obras relativas a la historia de Génova en la edad moderna cabe reseñar a GRENDI, E.: Introduzione alla storia moderna della Reppublica di Génova, Génova, 1976; a CONSTANTINI, C.: «La Reppublica di Genova nell'età moderna", en Storia D'Italia de G. Galasso, Vol. IX, Turin, 1978; y entre las publicaciones más recientes a BITOSSI, C.: Storia di Génova, Mediterraneo, Europa, Atlantico, Génova, 2003 (los siglos XVI y XVIII se tratan en pp. 325-508).

5 Vid. PACINI, A.: La Génova di Andrea Doria nell'Imperio di Carlo V, Florencia 1999, pp. 5-14. 
una prolongada alianza con España, estableciéndose su alternancia al frente del dogato y de las principales instituciones de la república ${ }^{6}$.

La Casa de Grimaldi, había tenido desde el siglo XII un protagonismo relevante en el gobierno de Génova y sus ramificaciones se extendían a Mónaco, uno de sus principales feudos, Nápoles, Sicilia, la Provenza y España. En el caso de Génova los Grimaldi habían ocupado tradicionalmente puestos de relevancia en las finanzas, en la administración de la república y en la Iglesia. En cuanto a ésta ultima cabe señalar que Girolamo Grimaldi (1674-1733), el hermano mayor de Francesco María Grimaldi anteriormente mencionado, no era sino el cuarto cardenal perteneciente a la familia. Los otros tres habían sido Girolamo Grimaldi (1527), Girolamo Grimaldi Cavalleroni (1643) y Nicola Grimaldi (1706). Además por parte materna hay que mencionar a Lázaro Opicio Pallavicini, primo de Jerónimo Grimaldi fallecido en 1786, que fue nuncio en España entre 1760 y 1767 y que sería nombrado cardenal en 1769, llegando a ocupar el cargo de secretario de Estado pontificio?. Esta tradición familiar y su condición de «segundón» parecen ser la explicación de que el joven Jerónimo se convirtiese en religioso cuando contaba catorce años de edad, aunque no mostraría gran inclinación por la vida eclesiástica, llegando a recibir órdenes menores cinco años más tarde. De igual modo parece evidente que la trayectoria diplomática de su padre, Francesco María, influyó de modo determinante en la trayectoria posterior del ya abate Grimaldi.

En este contexto, en el año 1734 Jerónimo Grimaldi, tras pasar algún tiempo en Roma, se pondría en marcha desde la capital pontificia hacia Madrid, donde debía seguir un proceso. Sin duda no sospechaba que lo que parecía inicialmente una estancia temporal en España se prolongaría durante más de cuatro décadas. El motivo oficial de este viaje no debe hacer descartar la hipótesis de que Grimaldi albergase en mayor o menor medida un segundo propósito, el de tantear la posibilidad de establecerse en la capital y pasar más adelante al servicio de España al igual que habían hecho otros tantos miembros de ilustres familias italianas a lo largo de las dos décadas anteriores. Y es que la presencia de italianos en la corte de Madrid era entonces un hecho habitual, puesto que la primera mitad del siglo XVIII había constituido un excelente caldo de cultivo para animar su emigración a España. La Guerra de Sucesión primero, el enlace matrimonial en 1715 de Felipe $\mathrm{V}$ con Isabel de Farnesio después, y por último la decidida política españo-

\footnotetext{
${ }^{6}$ La reforma de Andrea Doria supuso agrupar en los «alberghi» a veintitrés familias pertenecientes a los «vecchi» ó «nobili» y a otras cinco de los «nuovi» o «populari». La condición que se estableció para ello era la de tener al menos seis casas abiertas en Génova. Los dos bloques alternarían su posición relativa al alineamiento con España y esta a su vez se apoyaría en una u otra facción de acuerdo con sus intereses. CONSTANTINI, C.: «La Reppublica...», pp. 19-21. Sobre el reparto del poder entre las familias principales de la república de Génova en la Edad Moderna Vid. NICORA, M.: «La nobiltà genovese dal 1528 al 1700", en Miscellanea storica ligure, II, 1961 y GRENDI, E.: “Capitazioni e nobiltà genovese in età moderna", en Quaderni storici, n. ${ }^{\circ} 26$, (1974).

7 WEBER, C.: Legati e governatori dello Stato Pontificio: 1550-1809, Roma, 1994, pp. 159 y 714. Sobre el cardenal Pallavicini Vid. LUENGO, M.: Memoria de un exilio: Diario de expulsión de los jesuitas, Alicante, 2001, p. 417.
} 
la de reconquista de los espacios perdidos en Italia tras los tratados de Utrecht, constituyeron los tres factores determinantes de esta corriente ${ }^{8}$. Entre los emigrados italianos destacaba el elevado número de genoveses de las más diversas capas sociales ${ }^{9}$. Cabe citar a relevantes militares de marina como Carlos Grillo (fallecido en 1724), comandante de galeras, y Esteban Mari (fallecido en 1749), marqués de Mari y lugarteniente general de la Armada, que fue embajador en Venecia desde 1741; Francisco María Spinola (1675-1727), duque de San Pedro y capitán general de Valencia; Felipe Antonio Spinola (1665-1721), marqués de los Balbases, y su hijo Ambrosio (1696-1727), embajador en Portugal en $1727^{10}$.

No cabe duda de que la pertenencia de Jerónimo Grimaldi a una familia noble, su condición de genovés y la simpatía que solía suscitar su trato le facilitaron la rápida integración en la comunidad italiana en Madrid. El abate conseguiría entre sus miembros principales los primeros apoyos, que le servirían más adelante para impulsar su trayectoria al servicio de la corona española. A este respecto fue de particular importancia la protección que le dispensó el príncipe de Campoflorido, cuya influencia y habilidad para situar en buena posición a sus patrocinados eran notorias ${ }^{11}$. En el transcurso de los cinco años que siguieron a su llegada a España, hasta finales de 1739, Jerónimo Grimaldi sería progresivamente introducido en los círculos de influencia que manejaban los entresijos del poder en la corte de Felipe V.

Durante este periodo Grimaldi continuó manteniendo una estrecha relación con su patria, interviniendo cuando tuvo ocasión y siempre que fue requerido para

\footnotetext{
${ }^{8}$ Acerca de la emigración italiana en ese periodo vid. PRADELLS Y NADAL, J.: «ltalianos en la España del siglo XVIII», en GIMENEZ, E., LOZANO, M. A. y RIOS, J. A. (eds.) Españoles en Italia e italianos en España, IV Encuentro de investigadores de las universidades de Alicante y Macerata, Alicante, 1995, pp. 61-75.

${ }^{9}$ CIASCA, R.: Istruzioni e Relazioni degli ambasciatori genovesi, Vol. I, Spagna 1494-1617, Roma, 1951, p. 163. Sobre la alianza hispano-genovesa existe una abundante bibliografía entre la que mencionaremos por abordar el periodo que nos ocupa a QUAZZA, R.: Preponderanza spagnuola (15551700), Milán, 1951 y a GARIBBO, L.: La neutralità della Reppublica di Génova. Saggio sulla condizione dei piccoli stati nell'Europa del Settecento, Milán, 1972. Entre los estudios españoles destacaremos a HERRERO SANCHEZ, M.: «Génova y el sistema imperial hispánico», a ALVAREZ-OSSORIO, A. y GARCIA GARCIA, B. (ed.): La Monarquía de las Naciones, patria, nación y naturaleza en la Monarquía de España, Madrid, 2003, pp. 528-562; Mismo autor en «La república de Génova y la monarquía hispánica (siglos XVI-XVII)", en Hispania, LXV/1, no 219 (2005).

10 OZANAM, D.: "Les étrangers dans la haute Administration espagnole au XVIIle siècle", en Pouvoirs et société dans l'Espagne moderne. Hommage à Bartolomé Bennasar, Tolouse, 1993, pp. 215-229. La presencia de genoveses en los distintos territorios de la corona española ha sido objeto de varias publicaciones, de las que mencionaremos a MANTELLI, R.: Burocracia e finanze publiche nell regno di Napoli, Nápoles, 1981; a COLLADO VILLALTA, P.: «La nación genovesa en la Sevilla de la Carrera de Indias: declive mercantil y perdida de la autonomía consular», en Presencia italiana en Andalucía. Actas del I Coloquio Hispano-italiano, Sevilla, 1985, pp. 53-114; a; y a JANSSENS, P. DENEWETH, C.: «Les relations entre Gênes et les Pays-Bas espagnols (1555-1702). Etat de la recherche", en Belvederi, R. (ed.), Atti del IV congresso internazionale di studi storici. Rapporti GénovaMediterráneo-Atlántico nell'Età Moderna, Génova, 1990, pp. 241-242.

${ }_{11}$ Los Campoflorido son una buena muestra de la pujanza de las familias italianas en el reinado de Felipe V. Sobre su figura Vid. ALVAREZ-OSSORIO, A.: «El final de la Sicilia Española», VII Seminario Internacional: La pérdida de Europa, la Guerra de Sucesión por la Monarquía de España. Madrid, 2006.
} 
ello en favor de los intereses genoveses ${ }^{12}$. En el momento en que el abate llegaba a España la preocupación de la república en lo concerniente a las relaciones bilaterales se centraba más que en las cuestiones comerciales en otros asuntos. De ellos quizá el más apremiante era la necesidad de dar una respuesta a los requerimientos de Madrid para que Génova se prestase a apoyar las nuevas empresas en Italia, resultado de la firma del primer Pacto de Familia entre las potencias borbónicas. Otra cuestión que inquietaba a los gobernantes de Génova eran las posibles consecuencias de la implicación indirecta de España en la cuestión de la competencia comercial con Livorno. El puerto toscano era desde 1731 uno más de los feudos del infante don Carlos y este hecho había dado píe a que se extendiesen rumores sobre maniobras españolas para apoyar la insurrección corsa.

\section{DIPLOMÁTICO AL SERVICIO DE GÉNOVA}

En septiembre de 1739, Jerónimo Grimaldi fue designado por el dogo Constantini Balbi enviado extraordinario de la república ante Su Majestad Católica, recibiendo el 21 de diciembre de 1739 su primer despacho de la secretaría de Estado de Génova ${ }^{13}$. Es bastante probable que en esta decisión del dogato influyesen las gestiones de su familia, principalmente de su padre, que ocupaba una posición influyente en los círculos de poder de la república. A partir de su nombramiento y por espacio de más de seis años, hasta el 22 de febrero de 1746, Jerónimo Grimaldi pondría en práctica sus buenas dotes de observador del entorno que le rodeaba, como ponen de manifiesto los despachos semanales a Génova dando cuenta de las cuestiones más diversas, tanto referidas al ambiente que se respiraba en la corte de Madrid como a otros asuntos españoles y europeos y referentes a las Indias, y defendería los intereses genoveses allá donde fuese necesario.

La tarea de Grimaldi no sería sencilla, puesto que se le exigiría llevar a cabo las funciones de un embajador sin serlo realmente, para lo que habría de valerse únicamente de su intuición y de sus propias indagaciones y averiguaciones, obteniendo casi siempre la información que buscaba por vías indirectas, dado que el gobierno

\footnotetext{
12 Vid. QUAZZA, G.: La decadenza italiana nella storia europea. Saggi sul Sei-Settecento, Turin, 1971.

${ }_{13}$ Para la elaboración de este artículo ha sido determinante poder acceder a la correspondencia oficial de Jerónimo Grimaldi con las autoridades genovesas, incluida en la recopilación de R. CIASCA (en concreto los volúmenes VI y VII, correspondientes a España y que abarcan los años 1739 a 1746) de los despachos e instrucciones de los embajadores genoveses depositados en el Archivo Secreto de Génova (ASG). El Archivo de Estado de Génova está distribuido en tres grandes secciones: El Archivo Gubernativo, el Archivo Notarial y Jurídico y el Archivo del Banco de San Giorgio. En el Archivo Gubernativo figuran todos los papeles de la Señoría y el Archivo Secreto. En este ultimo puede encontrarse la correspondencia diplomática de 1500 a 1805 (Istruzioni del governo ai suoi ministri presso le corti estere), que incluye la mantenida con los representantes de la república en España (Spagna 1575-1663 y 1666-1784). Sobre estos archivos vid. CANALE, M.: «Degli archivi di Venezia, Vienna, Firenze e Génova» en Archivio Storico Italiano, Firenze, 1856; CIPOLLINA, M.: Brevi cenni sugii Archivi di Stato in Génova, Génova, 1887; y MAZZATINTI, G.: Archivi di Génova. Inventari dei degli Archivi d'Ítalia, Forli, 1891.
} 
español no estaba obligado a proporcionársela. Con estas limitaciones Grimaldi se vería en ocasiones en la nada sencilla obligación de defender decisiones de la república que no eran del agrado de Madrid, como se pondría de manifiesto ante la pretensión del rey de Nápoles de reclutar voluntarios genoveses, una concesión que se había hecho a España con carácter excepcional y durante un periodo limitado. A este respecto, en enero de 1740 Grimaldi informaba a la Signoría Serenissima de que se había entrevistado con el duque de Montemar, secretario de Guerra, para justificar la negativa de Génova a la petición napolitana alegando su terminante incompatibilidad con las leyes de la república ${ }^{14}$. Al mismo tiempo Grimaldi indicaba que había hecho llegar sutilmente a través de un amigo común al marqués de Villarías, secretario de Estado, una reflexión acerca de la conveniencia, dada la situación en Europa, de que «ad el Re di Spagna, ad el Re di Napoli nello stato in cui sono oggi le cose d'Europa di mantenersi amici li Principi d'Italia, i quali ancorchè piccoli possono ora essere di gran consequenza» ${ }^{15}$.

En octubre de 1739, apenas unos meses después de formalizar la aceptación del Tratado de Viena, por el que el infante don Carlos se había establecido en Nápoles y Sicilia a cambio de ceder al Imperio sus derechos sobre la Toscana y los ducados, España estaba de nuevo en guerra. Los esfuerzos militares españoles, inicialmente limitados al conflicto colonial y marítimo frente a Gran Bretaña que siguió al incidente de Jenkins, no tardarían en extenderse al teatro europeo, concretamente a Italia, como consecuencia de la participación española en la Guerra de Sucesión de Austria, que fue vista por Felipe V e Isabel de Farnesio como una ocasión idónea para proporcionar al infante don Felipe una posición parecida a la que se había logrado en Nápoles y Sicilia para su hermano, el infante don Carlos ${ }^{16}$.

Desde el inicio del conflicto sucesorio austriaco Génova intentaría mantener una prudente pero difícilmente sostenible postura de neutralidad, a pesar de las presiones tanto del bando borbónico como de los partidarios de los Habsburgo para que la abandonase ${ }^{17}$. En este sentido Grimaldi, consciente de la trascendencia del fallecimiento el 20 de octubre de 1740 del emperador Carlos VI, no tardaría en reclamar la atención tanto de sus interlocutores en Madrid como de la secretaría de Estado de Génova acerca de la gravedad y excepcionalidad de sus posibles

${ }^{14}$ Vid. CERRO NARGANEZ, R.: «José Carrillo de Albornoz y Montiel: un militar andaluz entre Cataluña e Italia», en Pedralbes, 18-II, (1998), pp. 531-535.

${ }^{15}$ Carta de Grimaldi a la secretaría de Estado de Génova de 18 de enero de 1740, incluida en CIASCA, R.: Istruzioni e Relazioni degli ambasciatori genovesi, Vol. VI, Spagna 1721-1745, Roma, 1968, pp. 249-251. En ella también da cuenta de los preparativos militares contra Inglaterra.

${ }_{16}$ Vid. BETHENCOURT MASSIEU, A.: Relaciones de España bajo Felipe V. Del Tratado de Sevilla a la Guerra con Inglaterra (1729-1739), Alicante, 1998.

17 En el transcurso de la Guerra de Sucesión de Austria estuvieron al frente de la república genovesa los dogos Nicolo Spinola (1740-1742), Doménico Canevaro (1742-1744), Lorenzo de Mari (1744-1746), Gian Francisco Brignole Sale (1746-1748) y Cesare Cattaneo della Volta (1748-1750). FORCHERI, G.: Doge, Governatore, Procuratori, Consigli e Magistrati della Reppublica di Génova, Génova, 1968. 
repercusiones en Italia ${ }^{18}$. A finales de noviembre Grimaldi informaba a Génova de que la corte española no solo pretendía optar a la candidatura del trono imperial, sino que había comenzado a movilizar sus recursos financieros y militares con vistas a una posible guerra. En ese momento Grimaldi consideraba que Felipe V e Isabel de Farnesio todavía no habían decidido si debía darse prioridad a aumentar el peso político en Italia del infante don Carlos con nuevas adquisiciones territoriales o a situar al infante don Felipe en alguno de los estados italianos, como finalmente sucedería ${ }^{19}$. Un mes más tarde, el 26 de diciembre, Grimaldi informaba de que en Madrid se sospechaba que Francia quería «imbrogliare le cose» refiriéndose a la sucesión de la corona imperial y del resto de estados hereditarios de la casa de Habsburgo ${ }^{20}$.

En enero de 1741 Grimaldi alertaba sobre los preparativos españoles de una expedición militar con destino a Italia. Consideraba que este hecho y las noticias sobre un posible arreglo entre las cortes de Versalles y Turín eran claros indicios de que la península italiana se vería de forma inminente convertida en el escenario de una guerra ${ }^{21}$. Esta connivencia de franceses y sardos no era bien vista en Madrid ya que se sospechaba que Fleury, anteponiendo ganar nuevos aliados frente a Austria a las pretensiones españolas, podía ofrecer al rey de Cerdeña el Milanesado austriaco, frustrando así el proyecto de Felipe V e Isabel de Farnesio de establecer al infante don Felipe en ese territorio. Grimaldi pensaba que los monarcas españoles se opondrían abiertamente a esa posibilidad y que no consentirían «aumentar en ningún modo la fuerza del rey de Cerdeña». En su correspondencia de los meses siguientes Grimaldi prestaría particular atención al seguimiento de las negociaciones entre Francia y Cerdeña y a las correspondientes reacciones españolas, consciente del riesgo de que Turín pudiese llevar a la práctica con ayuda de Versalles o de Viena sus deseos expansionistas a costa de

18 Grimaldi advertía a Génova de la conveniencia de «prendere quelle misure che più giudicherà a propòsito in un affare di tanta conseguenza e che riguarda, per una parte cosi di vicino, tutti i príncipi d' Italia». En CIASCA, R.: Istruzioni..., Vol. VI, p. xii.

${ }_{19}$ Carta de Grimaldi al gobierno de Génova de 20 de noviembre de 1740 (Idem., pp. 251-254). En relación con este asunto el marqués de Montijo, embajador en Viena, formuló una protesta contra la nueva ley de sucesión a la vez que presentaba a la Dieta germánica una extensa memoria del derecho de Felipe $\mathrm{V}$ a la totalidad de los dominios austriacos en virtud de pactos familiares entre Carlos $\mathrm{V}$ y su hermano Fernando. El monarca español era consciente de la nula vigencia de los derechos que alegaba y de su anterior reconocimiento de la Pragmática Sanción, pero buscaba con estas reclamaciones encontrar la justificación formal para la ocupación de los estados austriacos de Italia y conseguir así el establecimiento del infante don Felipe en Lombardía. En DEL CANTILLO, A.: Tratados, convenios y declaraciones de paz y de comercio que han hecho con las potencias extranjeras los monarcas españoles de la Casa de Borbón, desde el año 1700 hasta el día. Puesto en orden e ilustrados muchos de ellos con la historia de sus respectiva negociaciones, Madrid, 1843, pp. 350-352.

20 Carta de Grimaldi a la secretaría de Estado de Génova de 26 de diciembre de 1740, incluida en CIASCA, R.: Istruzioni..., vol. VI, pp. 254-256.

${ }^{21}$ Carta de Grimaldi a la secretaría de Estado de Génova de 16 de enero de 1741 (Idem., pp. 256-258). En ella también informaba de la mala acogida que había tenido en la Iglesia el nuevo impuesto del $10 \%$ sobre las ventas de bienes. Una de las gestiones exitosas de Grimaldi sería conseguir que ese impuesto no se aplicase a los comerciantes genoveses en Alicante y Valencia. 
Génova ${ }^{22}$. Este peligro era evidente a los ojos del abate, que no dudaría en calificar al rey sardo como «el único príncipe que podría ser un día fatal para los otros de Italia» ${ }^{23}$.

Especialmente atento a los mencionados preparativos militares españoles, Grimaldi informaría a Génova a finales de octubre de 1741 de que el cuerpo de ejército al mando de Montemar reunido en Barcelona sería escoltado por navíos de guerra franceses hasta La Spezia ${ }^{24}$. Una vez desembarcado en este puerto entre diciembre de 1741 y febrero de 1742 proseguiría a través de la Toscana y la Romaña hacia Ancona y Rímini ${ }^{25}$. Desde allí Montemar debía tratar de atraer a las fuerzas austriacas y sardas (en abril de 1741 Carlos Manuel III de Cerdeña había optado por unirse al bando austriaco) para alejarlas del Infante don Felipe ${ }^{26}$. El Infante encabezaba el segundo cuerpo español, al mando primero del conde de Glimes y después del marqués de la Mina, que había bordeado la costa mediterránea hacia la frontera franco-piamontesa para tratar de penetrar en Saboya ${ }^{27}$. Las operaciones en el Piamonte y Provenza serían motivo de varias quejas de Grimaldi a Campillo por la entrada de tropas españolas en territorio de la república de Génova, provocando las correspondientes reclamaciones de los sardos ${ }^{28}$.

A finales de marzo de 1742 Grimaldi recibía el encargo de su gobierno de realizar averiguaciones acerca de las intenciones españolas respecto a Córcega, en concreto se pretendía saber si sería posible que Madrid diese una garantía a la república sobre la posesión de la isla. Tras entrevistarse con Campillo la respuesta de Grimaldi fue la de que tal garantía no era posible en tanto continuase la estre-

22 Cartas de Grimaldi a la secretaría de Estado de Génova de 10 de abril, 2 de mayo, 4 de septiembre y 31 de octubre de 1741. Idem., pp. 259-267.

23 Idem., p. xiii.

${ }^{24}$ Carta de Grimaldi a la secretaría de Estado de Génova de 31 de octubre de 1741. Idem., pp. 267-269.

25 En DEL CANTILLO, A.: Tratados..., p. 353 y CERRO NARGANEZ, R.: «José Carrillo...», pp. 542-547. Montemar fue destituido por Campillo en diciembre de 1742 y relevado por Juan de Gages, partiendo poco después hacia el destierro. El motivo de su cese fue la impaciencia de los reyes antes su pasividad, como se había puesto de manifiesto en junio de 1742, cuando no llegó a presentar batalla en Bolonia frente a Carlos Manuel III de Cerdeña, provocando así la retirada del marqués de la Mina a Provenza al no poder sostenerse en Saboya. Vid. MELENDRERAS GIMENO, M. C.: Las campañas de Italia durante los años 1743-1748, Murcia, 1987.

${ }^{26}$ Este cambio de alianza se formalizó mediante la convención de Turín de 1 de febrero de 1742, que motivó la decisión de los aliados borbónicos de entrar en Italia por el norte. OZANAM, D.: La diplomacia de Fernando VI. Correspondencia reservada entre D. José de Carvajal y el Duque de Huescar, 1746-1749, Madrid, 1975, p. 5.

27 Grimaldi informaba del nombramiento del marqués de la Mina en su carta a la secretaría de Estado de Génova de 11 de diciembre de 1742, incluida en CIASCA, R.: Istruzioni..., vol. VI, pp. 284-286. Además de las fuerzas de Montemar y Glimes también se contaba con el apoyo de un contingente napolitano. Sin embargo, los británicos habían estando observando los movimientos españoles y en agosto de 1742 enviaron una escuadra de 13 navíos de guerra a Nápoles al mando del almirante Mathews, presentando un ultimátum al rey Carlos por el cual le conminaban a declararse neutral y a retirar esas tropas bajo amenaza de bombardear la ciudad, a lo que el soberano se vio obligado a acceder. FERNANDEZ, R.: Carlos III, Madrid, 2001, pp. 98-100.

${ }_{28}$ Como se muestra en las cartas de Grimaldi a la secretaría de Estado de Génova de 15 de mayo, 3 de julio (en la que hace referencia a las quejas del embajador de Cerdeña) y 23 de octubre de 1742. Incluidas en CIASCA, R.: Istruzioni..., vol. VI, pp. 273-284. 
cha relación entre Francia y España, dado que los franceses consideraban que la anexión de Córcega era una simple cuestión de tiempo ${ }^{29}$. Entretanto las revueltas en la isla seguían consumiendo las energías de la república sin que se avistase una solución ${ }^{30}$. De hecho muchos notables genoveses daban ya a Córcega por perdida y consideraban que prolongar su dependencia nominal de Génova era más una cuestión promovida por Gran Bretaña para evitar la expansión francesa en el Mediterráneo que un imperativo real para el país ${ }^{31}$. En otro orden de cosas Córcega no podía quedar al margen de la situación de guerra que existía en el Mediterráneo occidental, por cuyo control se enfrentaban franceses y españoles contra ingleses. Así, a principios de 1743 Grimaldi informaba de que se había entrevistado con Campillo a petición de este, muy quejoso por la supuesta condescendencia de las autoridades genovesas de la isla con los buques británicos y particularmente por su pasividad ante el incendio por los ingleses del navío español San Isidoro, internado en el puerto de Ajaccio. En sus explicaciones Grimaldi trataría de justificar en parte ese incidente a causa del comportamiento imprudente del capitán del San Isidoro, que meses antes se había incautado de armas y municiones en cuarteles del puerto corso en una flagrante violación de la neutralidad de la república, lo que ya había sido objeto de una protesta presentada por Grimaldi a Campillo en julio del año anterior ${ }^{32}$.

Llegado el otoño de 1743, cuando ya habían transcurrido dos años desde la muerte de Carlos VI, las autoridades genovesas continuaban viendo en la política errática de Carlos Manuel III de Cerdeña un grave riesgo para la integridad territorial y para la independencia de Génova, por lo que Grimaldi continuaría realizando gestiones para conseguir apoyos españoles, conociendo el escaso apego de la

${ }^{29}$ Carta de Grimaldi a la secretaría de Estado de Génova de 1 de mayo de 1742 (Idem., pp. 271-272). José del Campillo y Cossío, antiguo subordinado de Montemar durante la conquista de Nápoles, había redactado cuando era intendente general del ejército de Aragón un proyecto secreto para formar un ejército de 50.000 hombres con vistas a la conquista del Milanesado, Parma y Plasencia. El plan interesó vivamente a Isabel de Farnesio, que mandó llamarle a Madrid. En marzo de 1741 Campillo fue nombrado secretario de Hacienda y en los meses siguientes concentró también en su persona los cargos de secretario de Guerra, Marina e Indias, de consejero de Estado y de lugarteniente del Infante don Felipe, con lo que se convirtió de hecho en el director de la política española. El ascenso de Campillo implicó de paso la promoción de su protegido Ensenada, que fue designado secretario de Estado y Guerra del infante don Felipe. Sobre el pensamiento político de Campillo resulta de interés la reproducción de su obra Lo que hay de más y de menos en España, para que sea lo que debe ser y no lo que es, Alicante, 1999.

30 Giacionto Paoli y su hijo Pasquale habían huido a Italia en julio de 1739 tras la llegada de tropas francesas al mando de Maillebois, que permanecería en la isla hasta 1741. Tras su retirada Génova no pudo mantener el control de la isla, que pronto se volvió a levantar en armas. ARRIGHI, P. y POMPONI, F.: Histoire de la Corse, Paris, 1967. pp. 64-70. Una perspectiva italiana sobre la insurrección corsa puede encontrarse en VENTURI, F.: «Pasquale Paoli e la rivoluzione di Córsica», Rivista storica italiana, noㅡXXXVI, (1974).

${ }^{31}$ CONSTANTINI, C. «La Reppublica...» p. 431.

32 Grimaldi había comunicado a la secretaría de Estado de Génova el incidente de Ajaccio en su carta de 10 de julio de 1742. En otra de 5 de marzo de 1743 daba cuenta de las quejas de Campillo, que le recordaba el apoyo prestado en su momento por los ingleses al aventurero Neuhoff. Finalmente, en una carta de 28 de mayo de 1743 Grimaldi informaba de su reunión con Ensenada, en la que se había restado importancia al incidente del San Isidoro. Incluidas en CIASCA, R.: Istruzioni..., vol. VI, pp. 288-295. 
corte de Madrid hacia la de Turín. Durante un tiempo, cuando estuvo a punto de alcanzarse un acuerdo de paz en Europa, Grimaldi llegó a pensar que la política ambivalente de Cerdeña podía dejar a este reino al margen de los ajustes que por un momento pareció podían alcanzarse en Italia, alejando así el riesgo de expansión sarda hacia el sur. Sin embargo, poco tiempo después se desvanecería esa esperanza al tenerse noticias del acuerdo firmado en Worms entre Austria, Gran Bretaña y Cerdeña, lesivo para los intereses genoveses ${ }^{33}$.

El conocimiento de este acuerdo provocó una amarga decepción en Génova, que había intentado a toda costa dar seguridades a Viena y Londres, donde mantuvo en todo momento sus legaciones, de que permanecería neutral en el conflicto. La finalidad de esta actitud era evitar una posición común de ambas potencias con Cerdeña, deseosa de extender sus dominios en la costa ligur. En el caso de Austria se pretendía además conseguir una garantía que pudiese contrarrestar un posible intento francés de ocupar Génova, a pesar del débil apoyo que los Habsburgo habían prestado a la república con ocasión de la crisis de Córcega y de su política expansionista en Italia ${ }^{34}$.

En realidad, al margen de los esfuerzos diplomáticos genoveses tanto Gran Bretaña como Austria eran conscientes de la relación privilegiada que continuaba existiendo entre la Signoría Serenissima y la Corona española, lo que tácitamente la convertía en un enemigo potencial. Consecuentemente en septiembre de 1743, al tiempo que en Génova se confiaba todavía en conseguir el apoyo de Londres y de Viena, ambas cortes rubricaban con Turín el acuerdo de Worms, por el que Carlos Manuel III de Cerdeña unía definitivamente sus fuerzas a las de la emperatriz María Teresa a cambio, entre otras concesiones, de la promesa austriaca de entrega del marquesado de Finale ${ }^{35}$. La cesión se aseguraba a pesar de que ese territorio había sido vendido en 1713 por el emperador Carlos VI a la república de Génova según un contrato que fue ratificado en 1718 por la Cuádruple Alianza ${ }^{36}$. Por tanto el Finale pertenecía legalmente a Génova, de modo que la emperatriz no tenía autoridad para disponer de él ${ }^{37}$.

${ }^{33}$ En su carta de 22 de octubre de 1743 Grimaldi señalaba el grave perjuicio para la república que suponía la firma del tratado de Worms. Idem., pp. 301-304.

${ }^{34}$ CONSTANTINI, C.: «La Reppublica...», p. 432-433.

${ }_{35}$ Sobre la historia del Finale Vid. SILLA, G. A.: Storia del Finale, vol. I y II, Savona, 1964-1965 y BOTTA, L.: Storia di Finale, Savona, 1997. La obra más completa sobre la adquisición de este territorio por Génova sigue siendo el clásico de TALLONE, A.: Le cessioni del marchesato di Finale nel secolo XVIII, Pinerolo, 1897.

${ }^{36}$ La ratificación figura en el artículo IV del Tratado de 1718. DEL CANTILLO, A.: Tratados..., pp. 373 a 380 .

${ }^{37}$ La cuestión del Finale se remontaba a mediados del siglo XVI, cuando sus habitantes se levantaron contra el marqués Alfonso Del Carretto, protegido de Andrea Doria, y solicitaron la ayuda de la república, que ocupó el territorio en 1558. Doria, con la ayuda del embajador español, Figueroa, y del virrey de Milán, forzó la retirada de las tropas genovesas. Del Carretto fue repuesto y las esperanzas genovesas de anexión del marquesado se disiparon cuando en 1572 las tropas españolas entraron en el Finale con la excusa de evitar una intervención francesa. El dominio español sobre este territorio se consumaría en 1598 al rechazarse formalmente las peticiones genovesas de retrocesión. En CONSTANTINI, C.: 
El acuerdo de Worms, en definitiva, no representaba sino la confirmación del fracaso de la política de neutralidad genovesa, pero a pesar de que su firma suponía que la república se vería obligada a intervenir antes o después al lado de las potencias borbónicas, se pretendía escoger el momento y hacerlo cuando las condiciones fueran más favorables, tratando de evitar que la cuestión del Finale precipitase esa intervención.

Francia y España, por su parte, fijaron su atención en Génova una vez fracasada la aproximación a Turín. Si para la primera el factor principal era su posición geográfica con vistas a las operaciones en el norte de Italia, para la segunda tenían mayor importancia las cuestiones financieras y comerciales. A partir de ese momento ambas potencias no cejarían en sus intentos de forzar una decisión genovesa a su favor. De los halagos e insinuaciones se pasaría pronto a las presiones y a las amenazas veladas. Valga como muestra el despacho de 5 de octubre de 1743 en el que Grimaldi informaba a Génova de la sugerencia que le había trasladado el embajador francés en Madrid en el sentido de que la república debía proceder a armarse de inmediato para hacer frente a la segregación del Finale, aunque al abate no le pasaba inadvertido el hecho de que tras esa propuesta se ocultaba la intención francesa de despojar de Niza y Villafranca al rey de Cerdeña y no la inquietud por preservar la integridad territorial genovesa ${ }^{38}$. El despacho de Grimaldi del 12 de noviembre se refería a los comentarios del marqués de la Ensenada en el mismo sentido, dejando traslucir que Francia y España respetarían a Génova en función del apoyo que la república estuviese dispuesta a prestarles ${ }^{39}$. El embajador galo elevaría más adelante el tono de estas insinuaciones al señalar a Grimaldi que «in un prossimo avvenire Spagna e Francia avrebbero dimostrato praticamente alla Dominante la gravità dell'errore commesso nel non volere ar-

«La Reppublica...», pp. 60-61 y pp. 218-220. Sobe los orígenes de las reclamaciones genovesas Vid. ELMAYER, F.: Maximilian II, Philip II und Reichsitalien. Die Auseinandersetzungen um das Reichslehen Finale in Ligurien, Stuttgart, 1988; En cuanto a los proyectos españoles para el territorio resulta de interés el estudio sobre la intención de construir un puerto en Finale (en ANDRIANI, G.: Una vertenza ispanolombarda e genovese per la costruzione di un porto sulla costa del Finale, Génova, 1934).

${ }^{38}$ En palabras de Grimaldi la sugerencia francesa se resumía en que era «necessario che il Governo Serenissimo, con alcun plausibile pretesto, come sarebbe quello di togliere di Corsica molta gente male intenzionata nei torbidi di quel regno, si premunisse con alcune forze, facendo qualche nuovo bataglione di corsi, o, con altri simulati pretesti che mai mancano, si ponesse in istato di fare qualche resistenza ad alguna inaspettata violenza che volesse fare; che questa seria, ragionevole ed única precauzione era non solo necessaria, ma doveva essere anche acompagniata da altre circonstanze di tener le sue artiglierie in buono stato, munizioni da guerra sufficienti, e provvigioni di viveri», que merecía el comentario del abate de que «Mi si fece intendere, che il progetto della Francia sarebbe di togliere Villafranca e Niza al Re di Sardegna» y que «lo conobbi che la necesità di trovare artiglieria al di là dei monti, di avere qualche aiuto e amico che aiutasse dall'altra parta a superare i passi di Niza, erano i motivi che facevano tenere un tale ragionamento". Carta de Grimaldi a la secretaría de Estado de Génova de 5 de octubre de 1743, en CIASCA, R.: Istruzioni..., vol. VI, p. xiv.

39 Según Grimaldi Ensenada le manifestó que se sentía «costretto a fargli rilevare che i Principi che in niuna occasione sanno risentirsi, si trovano ad ogni ora esposti alle più enormi ingiustizie», y que estaba «convinto che uno Stato piccolo può farsi rispettare da altre potenze, o per l'aiutto che esso può offrir loro, o per il timore invece che poteva incutere». Carta de Grimaldi de 12 de noviembre de 1743, Idem., p. xv (la transcripción de la carta en pp. 305-309). 
marsi concludendo ese la pace con in nemici, a danno della Repubblica» ${ }^{40}$. Sin embargo, en otoño de 1743, en vísperas de una gran ofensiva borbónica en el norte de Italia, Génova todavía no se encontraba en una situación tan comprometida como para firmar una alianza arriesgada, que en caso de victoria austro-sarda podría imponerle unos sacrificios mucho más graves que la cesión del Finale. Esta situación explica la negativa de las autoridades genovesas a acceder a las reiteradas peticiones de Ensenada de que designasen un embajador con la debida acreditación, lo que le llevaría como reacción al marqués a negarse a recibir durante un tiempo a Grimaldi ${ }^{41}$. Los gobernantes de la república pretendían de este modo evitar verse comprometidos con la respuesta que un embajador oficial estaría obligado a dar en uno u otro sentido a las autoridades españolas. A cambio, un mero enviado extraordinario sin credenciales podía dar largas a la cuestión con mayor facilidad derivando cualquier asunto litigioso a Génova alegando carecer de capacidad de decisión, o contentando a sus interlocutores al darles la razón a título personal. Por otra parte no se percibía en ese momento riesgo de represalias de Versalles o Madrid, que solo llevarían a dificultar la posición de sus ejércitos en Italia al situarlos entre dos enemigos, y se consideraba que ambas cortes estaban poco dispuestas a aceptar las pretensiones expansionistas del rey de Cerdeña, lo que indirectamente garantizaba los intereses de Génova sin necesidad de implicarse en el conflicto ${ }^{42}$.

En este contexto la posición de Grimaldi se tornaba extremadamente delicada, obligado como estaba a cumplir las instrucciones de su gobierno y a intentar evitar posibles reacciones desfavorables en Madrid, máxime habida cuenta de que su nuevo interlocutor tras la desaparición de Campillo, el marqués de la Ensenada, era poco proclive a dejarse convencer por las alambicadas excusas que el abate se veía obligado a darle. A finales de enero de 1744 Grimaldi informaba de que Ensenada le había reclamado perentoriamente una explicación del motivo por el que Génova se negaba a dar una respuesta concreta a las propuestas de alianza de Francia y España. Grimaldi se lamentaba diciendo que «mi vidi costretto a dirne da me e come di mia reflessione» cuando Ensenada le insistió en que se presentaba una ocasión propicia porque «stavano cosi occupati gli Inglesi colle disposizioni di mare di Tolone, e i sardi con quelle di terra di Provenza, che al più non farebbero che minacciare, ma non mai sarebbero in istato di intraprendere», al tiempo que proclamaba «l'urgente necessità di maneggiare e tratare l'allenza proposta, senza la minima dilazione» y apuntaba los posibles beneficios territoriales para Génova dado que «il principale interesse della Reppublica non doveva essere quello del Finale, ma bensi di impediré l'ingrandimento del Re di Sardegna... i di profittare di cosi bella ocasione che le si presentaba di ingrandire considerevo-

\footnotetext{
40 Idem., p. xv.

${ }^{41}$ Este era uno de los asuntos que se trataban en la carta de 12 de noviembre mencionada en la nota 39.

42 En CIASCA, R.: Istruzioni..., vol. VI, p. xvi.
} 
lomente la medesima» ${ }^{43}$. En el mes de marzo y como respuesta a la afirmación de Grimaldi de que «la Repubblica intendeva armarsi e che anzi aveva già cominciato a farlo», Ensenada le requirió una relación pormenorizada por escrito de tales preparativos, a lo que el gobierno genovés no accedió, dejando a Grimaldi en una situación tan incomoda que se vio obligado a «fingirsi ammalato per evitare le dimande» ${ }^{4}$.

Por esas mismas fechas Grimaldi daba cuenta a Génova de que el rey de España había calificado la aparente calma de la república como de poco valor y de una aparente frivolidad ${ }^{45}$. A partir de entonces la preocupación principal de Grimaldi dejaría de ser responder con buenas palabras a las apremiantes reclamaciones de adhesión a la causa borbónica para centrarse en intentar convencer a Ensenada y al resto de sus interlocutores en la corte de Madrid de la buena fe con que actuaba su gobierno, ya que la lealtad de Génova pasaría a ser abiertamente cuestionada habida cuenta de que habían corrido noticias de que intentaba contemporizar al mismo tiempo con Borbones y Habsburgo, lo que era considerado los españoles como «ofensivo e irritante» 46 .

Entretanto Francia y España habían reanudado su ofensiva contra los sardos, sin que fuese previsible la ruta de sus ejércitos, que bien podrían seguir la costa ligur una vez ocupada Oneglia ${ }^{47}$. Es entonces cuando Grimaldi se posicionaría y llamaría la atención del gobierno de Génova sobre la conveniencia de cerrar un acuerdo de alianza con las potencias borbónicas a causa de «gli svantaggi che alla Repubblica deriverebbero da un eventuale dissapore con i Governi delle LL.MM. Cattolica e Cristianissima, giacchè esa verrebbe a trovarsi sola, in balia di

${ }^{43}$ Carta de Grimaldi a Génova de 28 de enero de 1744, (Idem., p. xv). En otra anterior, de fecha 17 de diciembre de 1743 (Idem., pp. 311-317) Grimaldi señalaba que Ensenada había ofrecido a Genova el Tortonés, el Alejandrino, el Langhe del Monferrato y los terrenos que pertenecían al rey de Cerdeña y estaban situados en la ribera de poniente.

44 Idem., p. xvii.

${ }^{45}$ Carta de Grimaldi a la secretaría de Estado de Génova de 10 de marzo de 1744, Idem., pp. 333-337. En otra de 1 de mayo resaltaría que Fernando VI se dolía de la actitud y del silencio del gobierno de la república, llegando a pensar que tenía el propósito de burlarse de sus amigos y aliados.

46 Vid. GARIBBO, L.: La neutralità...

47 La campaña de 1744 en Italia tampoco obtendría resultados definitivos. El 22 de febrero de 1744 las escuadras española y francesa fueron derrotadas en el Cabo Sicle por la flota británica del Mediterráneo. En cuanto a las operaciones terrestres, los hispano-franceses pusieron sitio en verano a la plaza de Coni, último obstáculo hacia las llanuras del Piamonte, pero a pesar de la derrota sarda el 29 de septiembre en Madonna del Olmo (a la que hacer referencia Grimaldi en su carta de 13 de octubre, en CIASCA, R.: Istruzioni..., vol. VI, pp. 420-42) fue preciso levantar el asedio, frustrándose los proyectos de ocupar el país y dejar fuera de la guerra a Carlos Manuel III. Meses antes el ejército español al mando de Gages se había concentrado en los confines del reino de Nápoles a la espera de la ayuda del infante don Carlos, que había revocado su neutralidad tras adherirse al segundo Pacto de Familia. El 11 de agosto de 1744 el ejército combinado hispano-napolitano fue sorprendido en Velletri por el austriaco Traun, que sufrió una decisiva derrota, disipando así cualquier amenaza de invasión del reino de Nápoles. Sobre el coraje mostrado por el infante don Carlos en la batalla afirmaría más tarde el rey de Cerdeña que «mostró gran firmeza de carácter y tuvo un comportamiento glorioso». Vid. BUONAMICI, C.: Comentarios o memorias de la sorpresa de Velletri y de la guerra de Italia. Año de 1744, (traducción del P. Bernardo Ariño de San Pablo), Madrid, 1788, pp. 76-86. 
nemici bien più terribili di Spagna e Francia, con il resultato d'aver perduto quella benevolenza e quei meriti che da tempo aveva saputo acquistarsi presso Casa Borbone», observaciones que serían tenidas en cuenta por la Signoría Serenissima y que sin duda influyeron en su decision de autorizar la apertura de negociaciones para alcanzar un acuerdo con Francia, España y Nápoles que garantizase la defensa de los intereses genoveses ${ }^{48}$.

Estas negociaciones, que comenzaron en agosto de 1744, se prolongaron durante varios meses y finalizaron con la firma el 1 de mayo de 1745 del Tratado de Aranjuez ${ }^{49}$. Se acordó mantener sus cláusulas en secreto hasta que de común acuerdo de todas la partes se decidiera hacerlas públicas ${ }^{50}$. En virtud de los términos del tratado Génova contribuiría a la coalición anti-austriaca reforzando el ejército español en el Norte de Italia con 10.000 soldados y 36 cañones, que serían mantenidos por cuenta de la república hasta final de año. A partir de 1746 ese mantenimiento correría íntegramente a cargo de España, que además se comprometía a pagar durante los dos años siguientes 30.000 pesos a Génova por la disponibilidad de esas fuerzas (artículos 2 y 4 del tratado). Francia, España y Nápoles garantizaban a perpetuidad la defensa del territorio de la república de Génova (Artículo 12), y los ejércitos español, francés y napolitano ocuparían militarmente la zona limítrofe perteneciente al reino de Cerdeña. Las plazas conquistadas por el ejército aliado quedarían en poder genovés, a excepción de Serravalle, Bardineto y Carosio, que pasarían bajo control de España (artículos 6 a 8 del tratado y los artículos separados y secretos numerados del 2 al 4).

Sin embargo, el tratado de Aranjuez no suscitó un apoyo entusiasta en Génova, donde las opiniones que propugnaban el mantenimiento de la neutralidad eran mayoritarias. De hecho los embajadores de la república insistirían sin mucho éxito ante Viena y Londres en que el apoyo militar de Génova estaba dirigido únicamente contra Cerdeña ${ }^{51}$. Por su parte, el confuso curso de las operaciones

${ }^{48}$ De la opinión de Grimaldi queda constancia en su carta de 30 de junio de 1744 . Por su parte el gobierno de Génova le encargaría por medio de sus instrucciones de fecha 6 de julio iniciar las gestiones para llegar a un acuerdo con España, a las que seguirían otras de 31 de julio ordenando posponerlas hasta que se aclarase el resultado de las operaciones en Piamonte. Finalmente, en el mes de agosto Jerónimo Grimaldi recibiría la plenipotencia del gobierno de Génova, adjuntando en su carta de 18 del mismo mes la respuesta de Villarías mediante la que se accedía a comenzar las negociaciones. CIASCA, R.: Istruzioni..., vol. VI, pp. 354-409.

${ }_{49}$ Los firmantes del acuerdo fueron el marqués de Villarías por parte española, el obispo de Rennes por la francesa, el príncipe de Jacchi por el reino de Nápoles y Jerónimo Grimaldi por la república de Génova. DEL CANTILLO, A.: Tratados..., p. 379. El texto completo del acuerdo era remitido por Grimaldi a la Signoría Serenissima en su carta de 5 de mayo de 1745. CIASCA, R.: Istruzioni..., vol. VI. pp. 486513.

50 En el tratado también se incluía una declaración de Jerónimo Grimaldi relativa a la restricción de la estancia en aguas territoriales genovesas de buques franceses que sistemáticamente llevaban a cabo actividades de contrabando, pero que finalmente no sería ratificada (este contencioso se solucionaría mediante la adición, en el año 1772, de un reglamento específico al tratado). DEL CANTILLO, A.: Tratados...., pp. 379-380.

51 GARIBBO, L.: La neutralitá..., pp. 126 y 127. Sobre las reacciones de partidarios y contrarios a la guerra Vid., VENTURI, F.: Settecento..., pp. 200 y siguientes. 
en Italia y la repentina muerte el 20 de enero de 1745 del emperador Carlos VII harían que Grimaldi mudase su opinión sobre las supuestas ventajas para Génova que podía conllevar una alianza con las potencias borbónicas, como pondría de manifiesto en su despacho de 9 de enero de 1745, en el que planteaba sus primeras dudas al respecto ${ }^{52}$. Cuatro meses después, cuando apenas habían transcurrido unos días desde la firma del tratado de Aranjuez, Grimaldi se lamentaría en su despacho semanal de «la nuova della gran catástrofe di Baviera», haciendo referencia al acuerdo alcanzado en Füssen entre el elector de Baviera, Maximiliano III, y la emperatriz María Teresa. Esta noticia suponía el fracaso del intento de Argenson, sucesor de Noailles al frente de la política exterior de Francia, de oponer a la candidatura de Francisco de Lorena, gran duque de Toscana y esposo de María Teresa, la del hijo de Carlos VII, Maximiliano III, quien sin embargo rechazaría la oferta y abandonaría la alianza con Francia para acercarse a Austria ${ }^{53}$. Esta situación provocaría tal «angustia» a Grimaldi que le hizo replantearse seriamente la oportunidad de la alianza rubricada en Aranjuez, que en aquel momento no parecía representar en modo alguno una garantía de resultados ventajosos para Génova ${ }^{54}$.

En otro orden de cosas, España tardaría poco tiempo en olvidar las clausulas económicas del tratado de Aranjuez, aplazando una y otra vez el pago de los subsidios periódicos prometidos a Génova. Este incumplimiento de los términos del acuerdo originaría la presentación de una memoria y de varias reclamaciones a Ensenada por parte de Grimaldi, de la que sirven de ejemplo sus despachos de 26 de junio y 3 de agosto de 1745 en los que daba cuenta a la Signoría Serenissima de que Ensenada le había manifestado que el impago se debía a que los genoveses no habían aportado la totalidad de las fuerzas previstas en el tratado ${ }^{55}$. Esta no sería sino la primera de una larga lista de excusas españolas para justificar el retraso en el pago de los subsidios pendientes, que se convertiría en la principal cuestión litigiosa entre Génova y España durante las dos décadas siguientes y pasaría a ser el asunto mencionado más a menudo en la correspondencia diplomática entre la república y sus embajadores en Madrid durante ese periodo.

Volviendo al curso de la campaña en Italia, a partir de la firma del tratado de Aranjuez pareció quedar decidido a favor de las potencias borbónicas. La colaboración genovesa fue determinante para facilitar a los ejércitos hispano-franceses obtener la victoria de Bassignana sobre los sardos a finales de septiembre de 1745, que fue seguida de la toma, entre otras, de las plazas de Alessandria, Valencia, Casale,

\footnotetext{
52 CIASCA, R.: Istruzioni..., Vol. VI, pp. 465-467.

${ }^{53}$ Mediante la firma de la Paz de Füssen el 22 de abril de 1745 Maximiliano III recuperaba Baviera a cambio de aceptar la Pragmática Sanción y de su voto favorable en la elección imperial para Francisco de Lorena, que sería coronado como Francisco I en septiembre de 1745. BROWNING, R.: The War of the Austrian Sucession, Nueva York, 1994, pp. 195-199.

${ }^{54}$ Esta preocupación se pone de manifiesto en el despacho de Grimaldi de 11 de mayo de 1745, en CIASCA, R.: Istruzioni..., Vol. VII, pp. 4-9.

55 Idem., pp. 9-23.
} 
Monferrato y que se culminó con la entrada en Milán de los ejércitos de la coalición a finales de $a n ̃ 0^{56}$. Como resultado del curso desfavorable de los acontecimientos el rey Carlos Manuel III de Cerdeña se mostró dispuesto a alcanzar un acuerdo con Luis XV, lo que permitiría a Argenson poner en práctica sus planes de poner fin a la guerra en la península italiana y de dar a la vez los primeros pasos hacia la creación de una confederación de estados como contrapeso de las ambiciones de Madrid y Viena ${ }^{57}$. Argenson dió instrucciones para que se iniciasen las negociaciones cuando las operaciones militares eran todavía favorables a las potencias borbónicas, actuando además a espaldas de España. De este modo Versalles no solo incumplía lo acordado en el tratado de Fontaineblau, sino que además dejaba de lado las reclamaciones territoriales españolas en favor del Infante don Felipe, puesto que por parte francesa se ofrecía a Carlos Manuel III de Cerdeña la práctica totalidad del Milanesado. Sobre la base de estas negociaciones se llegaría a un acuerdo teórico entre París y Turín el 25 de diciembre de 1745, poco después de la entrada en Milán de don Felipe, que en la práctica dejaba sola a España en Italia ${ }^{58}$.

Sin embargo, era evidente que la negociación secreta debía ser sometida en uno u otro momento al parecer de Madrid. Cuando así se hizo a principios de 1746 la reacción de los monarcas españoles al conocer sus términos fue de indignación por haber estado al margen de las conversaciones y por considerar que una vez más se habían dejado de lado sus aspiraciones territoriales en Italia. Como resultado, desde Madrid se pusieron en marcha de inmediato sendas iniciativas diplomáticas ante las cortes de Versalles y Viena. De la pésima acogida sobre las noticias del ajuste entre franceses y sardos daría cuenta Grimaldi en su despacho de fecha 29 de enero de $1746^{59}$.

\section{MISIÓN EN VIENA}

La misión de Viena requería la mayor discreción posible para que no llegase a conocimiento de Argenson la tentativa de negociar una paz separada con María

${ }^{56}$ Gages fue llamado para pasar con el refuerzo de una división genovesa al ejército del Norte, que bajo las órdenes del Infante don Felipe había partido de Niza el 1 de junio de 1745 . Al término de la primavera inició el descenso por Piamonte y Lombardía apoderándose de varias plazas, entre ellas Piacenza y Parma. El 28 de septiembre Gages venció a los austriacos en Bassignana, haciendo finalmente su entrada en Milán el Infante el 20 de diciembre. DEL CANTILLO, A.: Tratados..., p. 356.

57 Sobre la figura de Argenson Vid. COMBEAU, Y.: Le comte d'Argenson (1696-1764), Ministre de Louis XV, Paris, 1999.

${ }^{58}$ El encargado de las negociaciones por parte francesa sería Mr. Champeaux, embajador en Génova, que se desplazó a Turín a tales efectos, firmando el 26 de diciembre de 1745 los preliminares junto al plenipotenciario sardo, el marqués de Gonzaga. En ellos se indicaba que Carlos Manuel III de Cerdeña recibiría el Milanesado a la izquierda del Po y en la derecha hasta la Scrivia. Desde aquí y siguiendo por la derecha del este río e incluyendo el estado de Parma, el Cremonés y la parte del Mantuano comprendido entre el Oglio y el Po, se establecería el infante don Felipe. Otra parte del Mantuano junto con la eventualidad del ducado de Guastalla formarían el lote del duque de Módena, quedando para Génova una parte del Mantuano, el marquesado de Finale, el principado de Oveille y el castillo de Serravalle. DEL CANTILLO, M.: Tratados..., p. 357.

59 CIASCA, R.: Istruzioni..., Vol. VII, pp. 43-65. 
Teresa, lo que con toda seguridad irritaría a Luis XV. Pretendía evitarse esa situación a pesar de la escasa fiabilidad que como consecuencia de los preliminares de Turín inspiraba en ese momento la alianza con Francia. En este sentido parecía una decisión acertada la selección de un extranjero sin vinculación conocida con intereses españoles antes que la de un nacional para sondear a la corte de Viena sin despertar sospechas en el resto de legaciones diplomáticas en la capital imperial. Desconocemos hasta que punto esta circunstancia condicionó la decisión de escoger a Jerónimo Grimaldi o la medida en que en ella influyeron el cierto prestigio como diplomático que había adquirido en la corte de Madrid durante los años que representó a Génova y la acogida favorable que tuvieron sus gestiones en la negociación del tratado de Aranjuez. En cualquier caso no debe obviarse que en esa época era relativamente frecuente incorporar a extranjeros para paliar la carencia de nacionales con la experiencia y formación adecuadas y que Génova no había impuesto servidumbres legales a sus ciudadanos para entrar al servicio de otras potencias. Ensenada había recurrido en ocasiones anteriores a utilizar colaboradores nacionales y extranjeros para misiones similares, por lo que consideramos que pudo ser el inspirador de la idea. El caso es que Jerónimo Grimaldi continuó despachando semanalmente con la secretaría de Estado de Génova con plena normalidad hasta mediados de febrero de 1746, cuando con toda seguridad ya se había comprometido a encabezar la misión en Viena ${ }^{60}$. En cuanto a los primeros contactos al respecto, es probable que se remontasen a principios de enero de 1746, poco después de conocerse los preliminares de Turín, dado que Grimaldi, de naturaleza prudente, debió necesitar algún tiempo para meditar una respuesta que podía acarrearle beneficios inmediatos pero también ocasionarle perjuicios en el futuro. Tampoco es descartable que antes de decidirse consultase a su padre, que unía a su experiencia diplomática el conocimiento de primera mano de los círculos influyentes de la administración y la política de Génova. El el 24 de febrero de 1746 Villarías firmaba las instrucciones para Grimaldi, que partía de Madrid dos días más con una licencia de la secretaría de Estado de Génova, haciéndose cargo de sus funciones Giuseppe Ottavio Bustanzo ${ }^{61}$. Desde la capital de España se dirigiría a su ciudad natal, continuando después su viaje hacia Viena.

La posibilidad de que las autoridades genovesas pudiesen haber tenido conocimiento de las intenciones de Grimaldi antes de su partida parece quedar descartada en función del contenido de la correspondencia mantenida entre su sucesor, Giuseppe Bustanzo, y la Signoría Serenissima ${ }^{62}$. En los despachos de Bustanzo de los años 1746 a 1749 a los que se ha tenido acceso (los casi tres años que se prolongó

60 El último despacho de Grimaldi de que se tiene constancia es de fecha 15 de febrero de 1746 y en el informa de los detalles de la misión de Huescar ante la corte de Luis XVI.

61 CIASCA, R., Istruzioni..., Vol. VII, p. 65.

62 Giuseppe Ottavio Bustanzo fue nombrado secretario de la legación genovesa en Madrid en 1725. Reemplazó a Jerónimo Grimaldi como enviado extraordinario a partir del 26 de febrero de 1746 y fue designado ministro residente en mayo de 1749. Recibió sus credenciales en 1750 y los plenos poderes tres años más tarde. Bustanzo falleció en 1755, siendo sustituido por Giambatista Zoagli, que ocupó el puesto de ministro residente hasta diciembre de 1768. Idem., p. 65. 
la misión de Viena), las referencias a la situación de Grimaldi muestran que no conocía el motivo de su salida de Madrid ni el de su desplazamiento a la capital austriaca. La misma impresión se deduce de las instrucciones remitidas desde Génova en ese periodo, que tampoco hacen mención de que hubiese cambios en la dependencia del abate al que se llegaba incluso a dirigir alguna instrucción relativa al contencioso de los subsidios impagados. La conclusión a la que se llega es la de que Jerónimo Grimaldi no dio cuenta ni a las autoridades genovesas ni a su sucesor acerca de su misión, que mantuvo en secreto, y que no dejó de estar al servicio de Génova, al menos formalmente, hasta casi tres años más tarde. Esta afirmación no excluye la posibilidad de que su situación fuese conocida por algunos círculos influyentes de la república, que en todo caso mantuvieron la máxima reserva.

Retomando la misión de Grimaldi en Viena, recordaremos que con ella se pretendía abrir la vía de una paz separada con María Teresa. Esta iniciativa respondía, además de a los motivos anteriormente citados, al temor, pronto confirmado, de que la defección prusiana tras la reciente firma de la Paz de Dresde permitiese a Austria trasladar fuerzas de Alemania a Italia, lo que podría hacer peligrar las ventajas obtenidas en la península por los aliados borbónicos. Por ello se consideraba de la mayor importancia alcanzar un acuerdo para el cese de hostilidades en Italia a cambio del establecimiento del infante don Felipe en algunos de los dominios imperiales en Lombardía y en otros adquiridos por Carlos Manuel de Cerdeña en virtud de tratados anteriores. En el caso de Viena no era previsible que se produjese un conflicto como el que había afectado a Huescar y a Campoflorido, enviado extraordinario y embajador titular respectivamente, en el transcurso de la misión paralela que se había emprendido ante la corte de Versalles, puesto que desde la partida de la capital austriaca en enero de 1741 del encargado de negocios José Carpintero no existía representación diplomática española ante la corte de los Habsburgo. A cambio, la ausencia de una legación podría suponer dificultades para Grimaldi al carecer de apoyos para establecer los contactos oportunos en el gabinete de María Teresa, así como para remitir y recibir la correspondencia periódica que debía mantener con la secretaría de Estado ${ }^{63}$. Entre las instrucciones de Villarías a Grimaldi fechadas el 24 de febrero de 1746 se incluía la carta de designación firmada por Felipe V, cuyo contenido es el siguiente ${ }^{64}$ :

${ }^{63} \mathrm{La}$ documentación existente tanto en el AHN como en el AGS sobre la embajada de Grimaldi aparece bajo el epígrafe «Viena. Negociación reservada encargada a D. José Guillini», seudónimo que Jerónimo Grimaldi emplearía en toda la correspondencia cruzada con la secretaria de Estado con la finalidad de mantener en el mayor secreto posible su misión y los motivos que le llevaban a Viena.

${ }^{64}$ AHN, Estado, Legajo 3421, Expediente 5 (servicio exterior), carta de Felipe V a Grimaldi de fecha 24 de febrero de 1746 designándole embajador plenipotenciario. Con ella se le adjuntaban cartas a Grimaldi, también fechadas el 24 de febrero en EI Pardo, dandole pleno poder universal para tratar con los príncipes de Alemania, con el Emperador de Alemania y con Gran Bretaña. En otra carta, archivada en el mismo expediente y firmada por Fernando VI el 27 de agosto de 1746, se ratificaba a Jerónimo Grimaldi en su puesto (Felipe V había fallecido el 9 de julio). 
«Por la gracia de Dios por cuanto que siempre fue deseo del Rey mi padre, que esté con gloria, que las penosas fatigas de la guerra fuesen el medio más seguro para la paz y que desde la muerte del Emperador Carlos Sexto se procuró que tuviesen término nuestras pretensiones a la grande herencia de su Casa en su ajeno establecimiento del ser el Infante don Felipe, muy caro y amado hermano, que no han logrado hasta aquí las armas de esta Corona por varios motivos que alejan hoy más y más tan loable fin. Por tanto para cortar tan perniciosas oposiciones y que se consiga con la acción de nuestras fuerzas y las de la Emperatriz Reina de Hungría así aparte que venga a ser por último la tranquilidad de Italia y la de Europa conociendo en vos todas las apreciables circunstancias que se requieren para conducir y perfeccionar tan arduo empeño os elegimos y nombramos para que en Nuestro Nombre y representando Nuestra misma Persona tratéis con el ministro o ministros que afectase a este intento, que del mismo modo concretéis y firméis el tratado o tratados que conduzcan al principal objeto de servir a una solida paz por el establecimiento del mencionado Infante y todo lo que así concluyáis o forméis lo damos desde ahora por grato, lo observaremos y cumpliremos como si por Nos mismo lo hubiésemos tratado y confesado, concluido y firmado, para lo cual os damos toda esa facultad y pleno poder en la más amplia y completa forma, que de derecho se requiere y en fe de ello hicimos expedir el presente por nuestro consejero de Estado y primer secretario de Estado y de Despacho en El Pardo.»

Así, al mismo tiempo que en la practica se ponía fin a la dependencia de Jerónimo Grimaldi de la república de Génova, comenzaba un largo periodo de casi cuatro décadas en el que prestaría a la corona española numerosos servicios, en ocasiones discutidos pero no por ello desdeñables, y llegaría a convertirse en una de las figuras políticas mas destacadas del reinado de Carlos III. 
